\title{
The Impact of Smoking on Healthcare Provision
}

\section{Lori Delaney}

Faculty of Nursing, University of Canberra, ACT 2601 Australia

College of Medicine, Biology and Environment, Australian National University, Canberra ACT 0200, Australia

\section{Abstract}

Increasing health expenditure requires clinical leaders to have a functional understanding of health economics and its implications on the provisions of healthcare services. The subsequent health related illnesses associated with tobacco use, contribute to considerable economic burden to the health care system. Epidemiological analysis of tobacco use, suggests that it will become the leading cause of death in developed countries. The relative impact smoking has on the healthcare systems has been proffered to negate the burden of cost on health services secondary to reduced lifespans. Investing in chronic disease management programs such as pulmonary rehabilitation may reduce the impact of exacerbations of respiratory diseases on the individuals functioning, and alleviate some of the burden on acute care systems.

\section{Introduction}

A functional understanding of health economics has become increasingly important in a rapidly evolving healthcare environment. Over the past two decades, Australia has experienced a rapid increase in health care spending due to evolving medical technology, advances in clinical care and pharmacological management, along with an increase in life expectancy. Health economics is influenced by a number of factors such as the national and global economy, national policies aimed at maintaining the population's health, and health issues that have a substantial economic impact [1]. The use of tobacco has a significant deleterious impact on health,and as a result contributes to considerable financial burden on the provision of healthcare [2].

\section{Australian Healthcare System}

The management of Australia's healthcare system is financially regulated through a diffusion of responsibilities from federal governments, and the states and territories in which the individual hospitals are located. The commonwealth government provides subsidised programs for medical and pharmaceutical benefits schemes, in order to reduce the cost to health consumers. The underlying tenet of the Australian health care system is that it is accessible to all, regardless of the ability to pay. Subsequently, Australian residents can access health care services via public hospitals at no charge.

Although, Medicare provides a reduction in some medical costs which are funded by tax payers, there is an increasing discrepancy between increasing medical costs and the subsidises provided under Medicare [3]. As access to health services, such as General Practitioners (GP)is becoming increasingly less attainable due to a lack of resources, and increasing consultation costs, this contributes to increased pressure on hospital services. This has resulted in an increasing demand for hospitals to act as an intermediary between acute presentation management and GP provider [4]. As a result, there is the propensity for individuals with chronic health issues such as those related to tobacco use to present late with an acute onset of illness. In turn, requiring advanced medical interventions, leading to longer hospital admission, increased mortality risk, and increased medical expenditure [5].

These issues are further compounded by rising insurance premiums associated with private medical care, which has persistently increased in affordability over the years; for example between 1995-1996 private insurance premiums increased by $9.8 \%$ per year, which exceeded the
Consumer Price Index (CPI) by $6.9 \%$ per year [3].Comparatively, health spending per person increased at an average annual rate of $5.6 \%$ [3]. The rising costs of health insurance has been driven by a number of factors, including the rising costs of medical care, increased utilisation of private hospitals, and the effects of an aging population [3]. Conversely, there is increasing dissatisfaction with private insurance, attributed to patients' increasing out of pocket expenses [6]. As a result, public hospital systems are impacted by this lack of coverage provided by health insurance, with many privately insured patients electing to remain within the public healthcare setting.

\section{Economic and Financial Theory}

Consumers of the health care services are entitled to freedom of choice; freedom to choose services they access and the autonomy to engage in activities that may adversely affected their health, such as the use of tobacco and illicit drugs, and alcohol misuse. The subsequent health related illnesses associated with tobacco use, contribute to considerable economic burden to the health care system [7]. Many of the health issues attributed to tobacco have a delayed presentation, and as a result many individuals do not consider the future impacts that their current behaviours have on their health in later years. Although the behaviour is actively discouraged through Government restrictions regarding smoking venues and advertising, it can be viewed as being paternalistic, conversely from a health care perspective it is one of economic efficiency [8].

Smoking has been linked not only to a myriad of respiratory illnesses, but also to a variety of health conditions such as vascular disease [9], obesity [10], increased alcohol consumption [11], and heart disease [12]. This behaviour is more commonly linked to lower socio-economics groups who are less able to afford the impact that it has on their health, in terms of absenteeism from work, medication costs, and the needs for GP follow up [13]. Further, this activity has also been linked to significant adverse health effects on those exposed to passive cigarette smoke [14]. Subsequently, economic studies of

"Corresponding Author: Lori Delaney, Faculty of Nursing, University of Canberra, ACT 2601 Australia; E-mail: Iori.delaney@canberra.edu.au

Citation: Delaney L (2017) The Impact of Smoking on Healthcare Provision. Int $J$ Nurs Clin Pract 4: 257. doi: https://doi.org/10.15344/2394-4978/2017/258

Copyright: () 2017 Delaney. This is an open-access article distributed under the terms of the Creative Commons Attribution License, which permits unrestricted use, distribution, and reproduction in any medium, provided the original author and source are credited. 
health production commonly find cigarette consumption to be a significant and an important predictor of mortality rates.

The main issue confronted by healthcare providers and Governments is how to effectively and unobtrusively influence the private decision making of individuals regarding smoking. Economic models of addiction, such as the Melioration Theory explains addiction whereby, an informed, individual makes the decision of whether to smoke, weighing the benefits for doing so in terms of smoking enjoyment against the cost in terms of health and other associated risks [15]. The consequence of this decision is an irrational outcome, whereby there is a lack of foresight and internalising of the future consequences attributed to smoking [16]. In contrast, models of consumption, advertising, price and taxation help provide relatively unobtrusive and cost-effective means to intervene, and reduced smoking rates [16].An opposing, economic approach is to assume that there are no grounds to intervene if the consumers chooses rationally and voluntarily to smoke, are reasonably informed of the risks and creates no side effects for others; i.e. subjecting others to passive smoke [1]. This view rejects arguments not based on economic efficiency and paternalism. However, because cigarette consumption is addictive, the issues of rationality, volition, and information need to be scrutinised.

An epidemiological analysis [17] of tobacco use, has revealed that it will become the leading cause of death in developed countries, and is predicted that by 2030 tobacco will be responsible for 10 million deaths annually worldwide [18]. Smoking related diseases impact not only on Australia's burden of disease but also worldwide, particularly on low and middle income countries. This leads to considerable concern regarding the population's knowledge of the associated health risks, and whether individuals acknowledge the information regarding itsimpact on their health. A Chinese based study conducted by Izumi and colleague [19] revealed that $55 \%$ of non-smokers and $69 \%$ of smokers believed that cigarettes did minimal harm in terms of health. Similarly, in the high income populations, the health consequences of smoking were under-estimated, with many respondents failing to internalised risk or the potential for addictions [19].

\section{Tobacco use}

The changes in demography and technology have placed increased pressure on health budgets not only within Australia but worldwide. Mortality and fertility rates have decreased over recent decades, resulting in increased life expectancy, and an aging population that is likely to live to much older ages [20]. Furthermore, developments in knowledge and medical technology are contributing to an increased demand for health services, and in many cases to higher costs of providing such services [20]. As a result there is an emerging debate regarding how health care systems manage their budgets, in order to achieve dual objectives of maximising health gains against expenditure, and maintaining fair and equitable access to health services. The National Drug Strategy Household Survey [20] revealed that $19.5 \%$ of Australian smoked tobacco on a daily basis, whilst $3.6 \%$ reported occasional smoking which placed in a high risk category of developing chronic health conditions.In 2003, tobacco was responsible for $7.8 \%$ of the total burden of disease and injury in Australia, with lung cancer, chronic obstructive pulmonary disease, and ischemic heart disease accounting for $75 \%$ of the burden [21]. The associated health burden continued to rise with age, with the absolute burden concentrated between the ages of 55 and 75 years [21]. The impact of this on the healthcare system within Australia was reported as 15000 deaths attributed to active and passive smoking, and a cost to the hospital system $\$ 669.6$ million [22].

Researchers have debated about the relative impact smoking has on the healthcare systems, with one argument postulated by Manning [23], that smokers negate their burden of cost on health services due to a shorter lifespans. Further, the burdens are counteracted by the money gained by Government from tobacco taxes, and via smokers reduced access to pensions and decreased use of nursing home placements due to premature death [24]. Studies that purport smokers impose a reduced burden on health care than non-smokers are based primarily on a social analytic perspective, which is based solely on smokers dying at a younger age than non-smokers $[2,25]$. Although, smokers die at an earlier age, these discrepancies in age at the time of death are being reduced due to advances in medical care, pharmacological agents, and increasing rates of lung transplantation and improved survival rates. Nonetheless, it is widely acknowledged that cigarette smoking is strongly associated with increased morbidity and mortality due to a number of diseases [24].

Cross sectional research indicates that health hazards related to smoking, result in smokers consuming more medical resources than non-smokers, and subsequently increased medical expenditure $[19,26]$. In a study conducted by Rice [27], the differences in days spent in hospital and the number of visits to physicians was found to be statistically significant between smokers and non-smokers. The intrinsic costs associated with providing medical care to individuals with illnesses related to smoking are based on accessed health resources such as ambulatory care, costs of drug treatment, hospital care, rehabilitation, and long term home care.In addition, consideration needs to be given the relative costs incurred by losses in productivity, premature retirement and mortality. Contained within the literature is evidence of the socio-economic variations related to smoking and mortality [28]. Studies indicate that those within lower social groups have a greater prevalence and intensity of smoking, a higher all-cause mortality rate and lower rates of cancer survival [29]. In addition, lower socio-economic group have less financial resources to utilise to promote health, such as accessing medical services, and finances to pay for medications. Furthermore, health services are frequenting lacking in areas with low socio-economic status. The influence of smoking as a determinant of overall health inequalities is profound, in that if the entire population was non-smoking, mortality differences between social groups would be halved [30].

Chronic Obstructive Pulmonary Disease (COPD) is the leading cause of health impairment related to tobacco use, and imposes a significant burden in terms of disability and quality of life. It is predicted based on disability adjusted lifeyears (DALYs), that COPD will become the fifth major cause of disability and premature death by the year 2020 [31]. In an Australian context, COPD afflicts approximately 2 million Australians, equating to 1 in $5(18.6 \%)$ people aged 40 years and over [32]. The subsequent financial cost to the health care system was $\$ 8.8$ billion in 2008 , of which $\$ 0.9$ billion $(9.7 \%)$ was attributed to direct health system expenditure [32].

\section{Management}

Tobacco consumption is one of the main risk factors for death and contributes to the burden of diseases, both globally and nationally [31]. Almost 6 million people die annually secondary to tobacco consumption and exposure to passive smoke, which globally constitutes $6 \%$ of all deaths in women and $12 \%$ in men [32]. Although 
interventions such as, increase taxes on tobacco products; total ban on tobacco advertising; strong warnings on packaging; control of tobacco use in indoor locations; and health education have been effective to varying degrees to reduce the prevalence of smoking within Australia [33]. The predicted estimate that interventions such as increased taxes that would raise the price of cigarettes by $10 \%$ worldwide would result in an approximate $9-17 \%$ reduction in smoking, and prevent 10 million premature tobacco related deaths [34]. Comparatively, nonprice measures such as information campaigns, comprehensive bans on tobacco advertising and promotion, prominent warning labels, and smoking restrictions would reduce the current number of smokers by 23 million, and would avert five million deaths [34].

Although many of the health diseases attributed to smoking are incurable, many of the chronic health issues are manageable through effective primary care interventions. Effective management strategies provided within the primary care setting can reduce exacerbations and costly hospitalisation. Hospital admission rates frequently serve as a proxy for primary care quality. Henceforth, increased admission rates and healthcare costs endured as a result, maybe reflective of poor care co-ordination or care continuum [35]. Eliminating unnecessary care; that is care that is not clinically effective and cost effective, is a strategy that may facilitate a reduction in health related costs attributed to diseases linked to smoking [36]. Through structuring primary healthcare systems to reduce acute clinical admission may prove to be an effective strategy. Developing co-ordinated services between primary health care and acute care services via the use of electronic medical records, provides a method to make evaluation and treatment more efficient [37]. In addition, the implementation of care management programs, such as pulmonary rehabilitation, provide improved patient knowledge and adherence to treatment plans, and clinician adherence to guidelines which can improve outcomes and reduce costs [37]. Further, such programs provide individuals to consider to what ends they would want invasive medical treatment, or their preference to receive palliative measures.

Public health disease prevention and health promotion receives less than $2 \%$ of the budget [32]. Over the years there has been a call to redesign healthcare systems, in order to better meet patient's needs and improve outcomes. To accomplish this goal health care organizations are charged with identifying managerial strategies that facilitate the creation of care environments, or organisational support systems that ensure optimal care delivery [38]. Hence, a greater investment in primary health care strategies to manage chronic conditions resulting from tobacco use, may provide an important financial saving through avoiding acute hospital admissions, and improve patient compliance with preventative care protocols.

The underlying of premise of pulmonary rehabilitation is to reduce the impact of exacerbations of respiratory diseases on the individuals functioning, and alleviate some of the burden on acute care systems. Further the access to such services needs to be equitable regardless of where individuals reside. It is postulated, that this can be achieved through including the service under Medicare, when individuals are referred to pulmonary rehabilitation services via a medical practitioner. Presently, there are a number of poorly integrated and inefficient care providers which have been adversely impacted on by discrepancies associated, an example of which is access to Long Term Oxygen Therapy, and access to rehabilitation programs. Research undertaken, investigating the utility of pulmonary rehabilitation programs have revealed that individuals who took part in pulmonary rehabilitation programs, attended the Emergency Department fewer times, and were admitted $30 \%$ less often than patients who did not part take in a rehabilitation program [39]. Suggesting that these programs have considerable merit in term of improving patient's quality of life, reducing access to medical resources and decreasing healthcare costs.

Furthermore, the management of individuals who continue to smoke within the acute care system is generally inconsistent with hospital policy. As many hospitals have restrictions regarding smoking on hospital grounds, with some going as a far as suggesting that there will be on the spot fines for smoking on hospital premises. However, these are rarely enforced. Further, organisational support for policies regarding prescribing inpatients who smoke with nicotine replacement therapies is variable [40]. The inconsistent inpatient management of individuals, who are actively smoking, negates much of healthcare messages regarding its impact on health.

Smoking related diseases impose a considerable burden on the healthcare system through a continuum of acute services, chronic care, community services, allied health and specialist care. Whilst, numerous interventions have been instigated via federal government the most affective of which is increase in taxation, the adverse effects of the smoking on health is often not confronted until many years later. Through, greater investment in primary healthcare the management of these diseases may provide a reduction in health expenditure in the acute setting.

\section{Competing Interests}

The authors declare that they have no competing interests.

\section{References}

1. Folland S, Goodman AC, Stano M (2007) The Economics of Health and Health Care, 5th Edn., New Jersey: Pearson, Prentice Hall.

2. Barendregt JJ, Luc Bonneux MA, van der MaasPJ (1997) The Health Care Cost of Smoking. New England Journal of Medicine 337:1052-1057.

3. Hall J (1999) Incremental change in the Australian health care system. Health Aff (Millwood). 18: 95-110.

4. Healy J, Sharma E, Lokuge B (2006) Health systems in transition, Australia: The European Observatory on Health Systems and Policies.

5. Nagle A, Schofield M, Reman S (1999) Australian nurses smoking behaviour, knowledge and attitudes towards providing smoking cessation care to their patients. Health Promotion International 14: 133-144.

6. OCED (2011) Health at a Glance 2011: OECD Indicators, OECD Publishing.

7. Chisholm D, Evans D (2007) Economic evaluation in health: saving money or improving care? Journal of Medical Economics 10: 325-337.

8. Lucas G (2012) Saving somkers from themselves: The paternalistic use of cigarette use. University of Cincinnati Law Review 80: 1-55.

9. Katsikia N, Papadopoulou SK, Fachantidou AI, Mikhailidis DP (2013) Smoking and vascular risk: are all forms of smoking harmful to all types of vascular disease? Public Health 127: 435-441.

10. Stewart ST, Cutler DM, Rosen AB (2009) Forecasting the Effects of Obesity and Smoking on U.S. Life Expectancy. N Engl J Med 361: 2252-2260.

11. Lubin JH, Gaudet MM, Olshan AF, Kelsey K, Boffetta P, et al. (2010) Body mass index, cigarette smoking, and alcohol consumption and cancers of the oral cavity, pharynx and larynx; modeling odds ratios on pooled case control data. Am J Epidemiol 171: 1250-1261.

12. Huxley R, Woodward M (2011) Cigarette smoking as a risk factor for coronary heart disease in women compared with men: a systematic review and meta-analysis of prospective cohort studies. Lancet 378: 1297-1305.

13. World Health Organisation (2009) WHO Report on the Gobal Tobacco Epidemic. Geneva: World Health Organisation. 
13. Samet JM (2004) Samet, Passive smoking and health. Tobacco-science, policy and public health, pp. 281-313.

14. Chaloupka FJ, Warner KE (1999) The economics of smoking. In J. \&. Newhouse, The Handbook of Health Economics. University of Michigan.

15. Fishman PA, Khan ZM, Thompson EE, Curry SJ (2003) Healh care costs among smokers, former smokers and never smokers in an HMO. Health Serv Res 38: 733-749.

16. World Health Organisation (2008) Fresh and alive: Mpower, WHO report on the clobal tobacco epidemic. Geneva: World Health Organisation.

17. Peto R, Darby S, Deo H, Silcocks P, Whitely E, et al. (2000) Smoking, smoking cessation, and lung cancer in the UK since 1905: combination of national statistics with two case-control studies. BMJ 321: 323-309.

18. Izumi $Y$, Tsuji I, Ohkubo T, Kuwahara A, Nishino $Y$, et al. (2001) Impact of smoking habit on medical care use and its costs; a prospective observation of national health insurance beneficiaries in Japan. Int J Epidemiol 30: 616621.

19. Australian Insititute of Health and Welfare (2006) National Drug Strategy Household Survey. AlHW.

20. Begg S, Vos T, Barker B, Stevenson C, Stanley L, et al. (2007) The burden of disease and injury in Australia, Canberra: AlHW.

21. Collins D, Lapsley H (2008) The Costs of Tobacco, Alcohol and Illicit Drug Abuse to Australian Society in 2004/05. Canberra: Commonwealth of Australia.

22. Manning WG, Keeler EB, Newhouse JP, Sloss EM, Wasserman J (1989) The taxes of sin: do smokers and drinkers pay their way? JAMA 261:16041609.

23. Ruff LK, Volmer T, Nowak D, Meyer H (2000) The economic impact of smoking in Germany. Eur Respir J 16: 835-890.

24. Leu RE, Schaub T (1985) More on the impact of smoking on medical care expenditures. Soc Sci Med 21: 825-827.

25. Zhang X, Miller LS, Max W, Rice DP (1999) Cost of smoking to the medicare program. Health Care Financ Rev 20: 179-196.

26. Rice DP (2000) Cost of illness studies: what is good about then. Injury Prevention 6: 177-179.

27. Mackenbach JP, Stirbu I, Roskam AJ, Schaap MM, Menvielle G, et al (2008) Socioeconomic inequalities in health in 22 European countries. N Engl J Med 358: 2468-2481.

28. Woods LM, Rachet B, Coleman MP (2006) Origins of socio-economic inequalities in Cancer survival: A review. Ann Oncol17: 5-19.

29. Jha P, Gajalakshmi V, Gupta PC (2006) Prospective study of one million deaths in India. Rationale, design and validation results. PLoS Medicine 3: e18.

30. Halbert RJ, Natoli JJ, Gano A, Badamgarav E, Buist AE, et al. (2006) Global burden of COPD: systematic review. Eur Respir J 28: 523-532.

31. The Australian Lund Foundation (2008) Economic impact of COPD and cost effective solutions. Adeliaide: Access Economics.

32. WHO (2010) Noncommunicable diseases report: Burden: mortality, morbidity and risk factors. Geneva: WHO.

33. WHO (2011) Assessment of the Economic Costs of Smoking, Geneva: World Health Organisation.

34. Starfield B (2005) Contribution of Primary Care to Health Systems and Health. Milbank Q 83: 457-502.

35. U.S. Department of Health- Human Services (2011) Report to Congress: National Strategy for Quality Improvement in Health Care. Washington: U.S. Department of Health \& Human Services.

36. Kelley R (2009) WHITE PAPER: Where can $\$ 700$ billion in waste can be cut annually from the U.S. healthcare system. Healthcare analytics.

37. Roski J, Jeddeloh R, An L, Lando H, Hannan P, et al. (2003) The impact of financial incentives and a patient registry on preventive care quality: increasing provider adherence to evidence based smoking cessation practice guidelines. Preventive medicine 36: 291-299.

38. William DC, Man MI, Polkey N, Donaldson BJ, Gray JM (2005) Community pulmonary rehabilitation after hospitalisation for acute exacerbations of chronic obstructive pulmonary disease: randomised. BMJ 329: 1209.

39. Tengs TO, Adams ME, Pliskin JS, Safran DG, Siegel JE, et al. (1995) Five hundred life saving interventions their cost effectiveness. Risk Anal 15: 369-390.

Int J Nurs Clin Pract

ISSN: 2394-4978

\section{0.}

